\title{
CIRURGIA APICAL: TÉCNICAS, TECNOLOGIA E MATERIAIS NA BUSCA DO SUCESSO
}

\section{APICAL SURGERY: TECHNIQUES, TECHNOLOGY AND MATERIALS IN THE PURSUIT OF SUCCESS}

\author{
Carmo Antonio Aun * \\ Carlos Eduardo Aun * \\ Giulio Gavini **
}

\begin{abstract}
RESUMO
A evolução da tecnologia e de pesquisas científicas trouxe novas possibilidades para o cirurgião-dentista aprimorar sua terapêutica e maximizar resultados favoráveis perante diversas patologias. A Endodontia vem se firmando como especialidade de alto índice de sucesso, porém o fracasso ainda existe, principalmente nos casos de retratamento com lesão e obturação insatisfatória e em cirurgias apicais envolvendo infecções refratárias. Após revisão da literatura, observa-se que vários autores, ao longo dos anos, discutem a indicação e a técnica cirúrgica, que envolve diretamente a apicectomia, o retropreparo, o tratamento da superfície apical ressectada, a obturação retrógrada, o material retrobturador e a microinfiltração que esse material possa apresentar. O uso de ultrassom no corte do ápice e a possibilidade de se utilizar a irradiação laser no retropreparo, visando uma profunda desinfecção e possível diminuição da permeabilidade dentinária, chamaram a atenção da comunidade científica, gerando uma onda de estudos direcionados nesse sentido. Pode-se observar uma grande variedade de resultados e propostas quando do manejo do ápice durante a cirurgia apical, assim como contradições referentes à indicação cirúrgica.
\end{abstract}

DESCRITORES: Apicectomia • Lasers • Endodontia.

\section{ABSTRACT}

The evolution of technology and scientific research has brought new possibilities for the dental professionals to improve their therapy and maximize favorable results against various pathologies. Endodontic therapy shows a high rate of success, but failure still exists, especially in cases of retreatment with lesion and unsatisfactory obturation and in apical surgery involving refractory infections. After reviewing the literature, it is observed that many authors over the years discussed the indications and surgical technique of this kind of procedure, which directly involves the apicoectomy, retrofilling cavity preparation, the refinement of apical ressected surface, retrograde filling, the retrofilling material microleakage. The use of ultrasound in the apex ressection and the possibility of using the laser irradiation in retrofilling cavity preparation, seeking a thorough disinfection and possible reduction of dentin permeability, drew attention of the scientific community, generating a wave of studies about this topics. A wide variety of results and proposals is discussed when the management of the apex is during in an apical surgery, and contradictions regarding to the surgical indication.

DESCRIPTORS: Apicoectomy • Lasers • Endodontics.

\footnotetext{
* Doutorando em Endodontia pela Faculdade de Odontologia - Universidade de São Paulo Faculdade de Odontologia da Universidade de São Paulo FOUSP carmoaun@usp.br

** Prof. Associado da disciplina de Endodontia da Faculdade de Odontologia - Universidade de São Paulo Faculdade de Odontologia da Universidade de São Paulo - FOUSP ceaun@usp.br

*** Prof. Associado da disciplina de Endodontia da Faculdade de Odontologia - Universidade de São Paulo Faculdade de Odontologia da Universidade de São Paulo - FOUSP ggavini@usp.br
} 


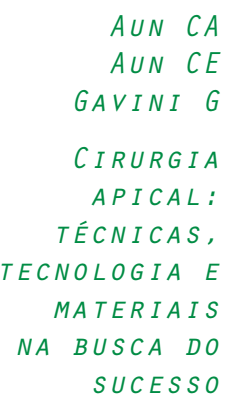

40

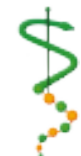

REVISTA DE ODONTOLOGIA DA UNIVERSIDADE CIDADE DE SÃO:

PAULO

$2010 ; 22(1): 39-$

49 , JAN-ABR:

\section{IN T RO DUÇÃO}

Mesmo com o aumento do índice de sucesso da terapia endodôntica ao longo dos anos, o fracasso ainda persiste. Contudo, após uma adequada abordagem conservadora, certas condições extremas requerem a intervenção cirúrgica periapical como última tentativa de manutenção do dente. No entanto, a técnica de manejo do ápice ressectado e o material retrobturador podem definir o sucesso ou fracasso da cirurgia apical.

A utilização de brocas carbide multilaminadas em alta rotação refrigerada, o corte do ápice perpendicular ao longo eixo da raiz, o refinamento da apicectomia com brocas de acabamento e a utilização de pontas ultrassônicas específicas para o retropreparo foram grandes inovações que comprovadamente podem melhorar o prognóstico da cirurgia apical. Conjuntamente, o desenvolvimento e avaliação do MTA como novo material retrobturador, com características adequadas para utilização em cirurgia apical, é de grande importância na tentativa de selar o sistema de canais remanescentes.

A retrobturação, a ser realizada em ambiente de difícil acesso e na presença de sangue, requer o uso de um material selador adequado a esse meio. Idealmente, tal material deve minimizar ao máximo a microinfiltração, ter estabilidade dimensional, radiopacidade, atividade antimicrobiana, não sofrer alteração em meio úmido e ser biocompatível. Vários tipos de materiais foram testados e usados em retrobturação nos últimos 20 anos, contudo o MTA parece ser continuamente indicado para essa finalidade, pois apresenta boa capacidade seladora apical, boa radiopacidade, boa estabilidade dimensional, excelente tolerância tecidual e o mais importante: sua presa completa requer $100 \%$ de umidade.

Outra possibilidade de favorecer o sucesso em cirurgias apicais foi observada quando os lasers de alta potência foram introduzidos na Endodontia. Sua principal função é a possibilidade de descontaminar a superfície apical ressectada e a retrocavidade previamente à retrobturação, efeito este comprovado ao longo de
15 anos de estudos.

Por meio da capacidade de aumentar significativamente a temperatura em seu foco de ação, a irradiação com os lasers Nd:YAG (1064 nm) ou Diodo GaAlAs $(810 \mathrm{~nm})$ provoca esse efeito antimicrobiano e, ainda, uma fusão e derretimento superficial dos túbulos dentinários, podendo reduzir a permeabilidade dentinária na região irradiada. O estudo de Aun e Silva ${ }^{1}$ (1995) foi um dos pioneiros no Brasil a reportar os efeitos do laser de alta potência sobre a microinfiltração retrógrada. Aun et al. ${ }^{2}$ (2004) avaliaram, in vitro, a capacidade seladora, perante a infiltração com corante, de materiais retrobturadores com a irradiação prévia de laser $\mathrm{CO}^{2}$, mostrando ser a irradiação laser com o MTA o grupo com menor infiltração linear e por área, de acordo com a metodologia do estudo. A diferença dos grupos MTA diante dos outros materiais foi estatisticamente significante, porém o mesmo não se observou em relação à irradiação ou não de laser $\mathrm{CO}^{2}$. Recentemente, Aun et al. ${ }^{3}$ (2004) demonstraram uma significante redução na microinfiltração de corante em retrobturações de MTA com a prévia irradiação dos lasers de Nd:YAG e Diodo 810nm.

Com base nesses dados e evidências, considera-se necessária uma revisão específica da literatura, onde artigos nacionais e internacionais possam ser analisados e discutidos com enfoque em aprimorar a cirurgia apical e seus métodos de estudo e aplicação.

\section{REVISÃO DA LITERATURA}

Índices de sucesso e divergências relacionadas a retratamento não cirúrgico e cirúrgico.

Analisando estatisticamente 1300 casos de retratamento cirúrgico ou não cirúrgico, Allen et al. ${ }^{4}$ (1989) examinaram prontuários e radiografias de retratamentos endodônticos e tabularam diversos fatores que poderiam ter afetado o índice de sucesso. Os resultados foram analisados sob diversos testes estatísticos. Os retratamentos realizados com guta-percha alcançaram um índice de $72,2 \%$ de sucesso, enquanto os tratados cirurgicamente com retrobturação chegam a $60 \%$, não havendo diferença estatística entre eles. 
Os autores colocam que mais de $50 \%$ dos retratamentos necessitou de alguma complementação cirúrgica.

Revisando aspectos clínicos acerca da apicectomia e manejo da superfície apical ressectada, Gutmann e Pitt Ford ${ }^{5}$ (1993) discorreram sobre diversos tópicos relacionados às dificuldades, variabilidades e técnicas que cercam esse tipo de procedimento. Dentre eles, os principais: indicações, consequências, técnica, anatomia macroscópica e microscópica da superfície ressectada e suas considerações clínicas. Ressaltam o uso racional da indicação e uma técnica apurada e atual embasada em artigos científicos e experiência clínica. Concluem que a apicectomia, ou ressecção apical, é um procedimento altamente desejável, do ponto de vista clínico e biológico, quando se busca minimizar os fatores irritantes locais e melhorar a cura periapical.

Comparando os resultados de retratamentos não cirúrgicos ou cirúrgicos em um estudo clínico randomizado, Kvist e Reit ${ }^{6}$ (1999) procuraram achar uma diferença sistemática entre os métodos. Quarenta e cinco dentes anteriores foram tratados cirurgicamente e 47 não cirurgicamente. Os fatores de randomização foram: tamanho da radioluscência periapical, a posição apical e a qualidade técnica da obturação. Todos pacientes foram controlados clínica e radiograficamente por 6, 12, 24 e 48 meses. Em 12 meses de avaliação, uma taxa de cura estatisticamente significante $(p<0.05)$ foi atribuída ao grupo cirúrgico, quando comparado ao não cirúrgico. No tempo final de 48 meses, essa diferença já não existia mais e o índice de sucesso ficou entre $50-60 \%$. Os autores não encontraram diferenças sistemáticas entre os métodos.

Mead et al. ${ }^{7}$ (2005) procuraram por artigos científicos clínicos que conectassem sucesso e fracasso de cirurgias periapicais e retratamentos e atribuíram níveis de evidência para esses estudos. Uma escala estratificada de níveis de evidência foi criada para determinar o grau de importância e confiabilidade dos estudos, baseando-se em seu grau de evidência clínica, de acordo com o método de seleção, controle e avaliação dos casos. No total, 79 artigos foram selecionados e a nenhum foi atribuído o grau máximo de nível de evidência. Para 7 deles foi atribuído o $2^{\circ}$ nível, para 12 o $3^{\circ}$ nível e para 60 o $4^{\circ}$ nível. Os autores concluíram que pouquíssimos estudos de alto nível comparam o sucesso e fracasso de cirurgias apicais versus retratamentos, advertindo que os principais fatores limitantes dos estudos são o uso de radiografias e o tempo de avaliação. Concluíram, ainda, que a cirurgia periapical parece ser efetiva para salvar dentes humanos naturais.

Na tentativa de encontrar, clínica e radiograficamente, fatores que possam predicar a cura de tratamentos endodônticos cirúrgicos, von Arx et al. ${ }^{8}$ (2007) acompanharam, durante um ano, 191 dentes que sofreram apicectomia, retropreparo ultrassônico e retrobturação com Super-EBA, MTA ou um compósito. Diversos dados, obtidos no pré e pós-operatório sobre os pacientes e seus dentes tratados foram tabulados e submetidos a testes estatísticos. O índice de sucesso geral foi de $83,8 \%$, e o fator "dor no exame pré-operatório" foi o único predicativo que significativamente $(p=0,04)$ diminuiu a taxa de cura das cirurgias apicais.

Técnica operatória referente ao manejo do ápice e retrocavidade

A topografia de superfícies apicais ressectadas e refinadas com diversos tipos de brocas foi avaliada por Morgan e Marshall ${ }^{9}$ (1998). Três grupos experimentais $(n=12)$ foram divididos de acordo com o tipo de broca para ressecção: broca de Lindman, broca multipropósito e broca \#57, todas de carbide multilaminadas. Após a ressecção, réplicas da superfície apical eram obtidas. Em cada grupo, dois subgrupos foram criados de acordo com a broca de refinamento: carbide multilaminada fina ou broca diamantada de acabamento. Novas réplicas foram obtidas, todas foram examinadas em microscópio. A broca de multipropósito produziu a superfície mais lisa e plana. A broca de refinamento de carbide produziu as superfícies mais lisas.

Testori et al. ${ }^{10}$ (1999) procuraram avaliar o índice de sucesso de 302 cirurgias apicais, tendo como diferencial o tipo de retropreparo: com brocas ou pontas ultra-
AUN CA

AUN CE

GAVINI G

CIRURGIA

APICAL:

TÉCNICAS,

teCNOLOGIA E

MATERIAIS

NA BUSCA DO

SUCESSO
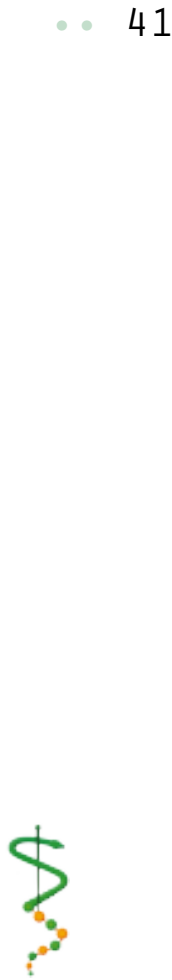

REVISTA DE ODONTOLOGIA DA UN I VERS I DADE CidAdE DE SÃO PAULO

$2010 ; 22(1): 39$ 49, JAN-ABR 
AUN CA

$A \cup N \quad C E$

GAVINI G

CIRURGIA

APICAL:

TÉCNICAS,

TECNOLOGIA E

MATERIAIS

NA BUSCA DO

SUCESSO

42

REVISTA DE:

ODONTOLOGIA DA

UNIVERSIDADE

CIDADE DE SÃO

PAULO

$2010 ; 22(1): 39-$

49, JAN-ABR sônicas. Os resultados foram avaliados radiograficamente por 4,6 anos em média e classificados em 4 grupos (da cura total até o fracasso). $O$ índice de sucesso nos casos tratados com brocas foi de $68 \%$ e com ultrassom de $85 \%$, havendo diferença significante. Os autores também observaram que o sucesso aumentou quando o tempo de avaliação se estendeu.

Num estudo que avaliou a incidência de microcracks, a microinfiltração de materiais retrobturadores e a microestrutura dos materiais retrobturadores, TobómArroyave et al. ${ }^{11}$ (2007) procuraram por fatores que poderiam afetar a qualidade do selamento retrógrado. Dois grupos (n = 46) foram divididos de acordo com o material obturador: sistema Thermafil ou guta-percha condensada lateralmente. Todas as raízes sofreram apicectomia com brocas diamantadas em alta rotação e retropreparo com pontas ultrassônicas. Três novos subgrupos $(n=24)$ foram criados de acordo com o material retrobturador: IRM, Super-EBA e MTA. Após retrobturação, todas as raízes permaneceram em Indian ink por 7 dias e as superfícies avaliadas. Os espécimes foram seccionados longitudinalmente e observados em MEV. Os autores relatam que, apesar da espessura de dentina ser similar nos dois grupos, o grupo Thermafil apresentou significativamente $(p<0,05)$ mais microcracks. Super-EBA e IRM apresentaram significativamente melhor adaptação e menor infiltração que o MTA. O maior tempo requerido pela ponta ultrassônica para remover a obturação Thermafil, durante o retropreparo, pareceu ter relação direta com a maior formação de microcraks.

Propriedades e uso do MTA como material retrobturador

Torabinejad et al. ${ }^{12}$ (1993) avaliaram a capacidade seladora do MTA, Super-EBA e amálgama, como materiais retrobturadores, perante a infiltração de corante. Com grupos de 10 raízes processadas até o retropreparo com brocas, as retrobturações foram realizadas e os espécimes permaneceram em Rodamina B por $24 \mathrm{~h}$. Os autores concluíram que o MTA apresentou significativamente $(p<0,05)$ menor microinfiltração e melhor adaptação marginal.

Continuando o estudo anterior, Torabinejad et al. ${ }^{13}$ (1994) verificaram se a presença ou não de sangue na retrocavidade poderia afetar a microinfiltração do MTA, amálgama, Super-EBA e IRM. Grupos de 10 raízes apicectomizadas e retropreparadas com brocas foram retrobturadas, com os respectivos materiais, na presença constante ou não de sangue. As raízes foram imersas em azul de metileno a $1 \%$ por 72 horas, seccionadas e analisadas, revelando ser o MTA o material que apresentou o menor nível de microinfiltração, tanto na presença como na ausência de sangue, porém, não houve diferença estatística entre os materiais.

Torabinejad et al. ${ }^{14}$ (1995c) também investigaram a adaptação marginal de IRM, Super-EBA, MTA e amálgama quando usados como materiais retrobturadores. Quarenta dentes foram processados até o retropreparo com brocas e receberam os materiais. Todos foram observados em MEV. Outros 48 dentes foram retrobturados da mesma maneira, tiveram impressões em tomadas resina e as réplicas observadas em MEV. Os resultados demonstraram que o MTA foi significativamente $(p<$ $0,05)$ superior na capacidade de se adaptar às paredes da retrocavidade.

Para desmistificar as propriedades físicas e químicas do MTA, Torabinejad et al. ${ }^{15}$ (1995a) determinaram sua composição química, $\mathrm{pH}$ e radiopacidade, além de comparar seu tempo de presa, resistência a força compressiva e solubilidade com o amálgama, IRM e Super-EBA. Utilizandose um espectrômetro dispersivo de raio- $x$ em conjunto com um MEV, um pHgâmetro e diversos métodos avaliativos, os resultados mostraram que as principais moléculas do MTA são íons cálcio e fósforo. $\mathrm{O}$ pH inicial foi de 10,2, passando para 12,5 após 3h de manipulação. O MTA se mostrou mais radiopaco que o Super-EBA e IRM e seu tempo de presa foi de $2 \mathrm{~h}$ e 45 min. O MTA mostrou a menor resistência à força compressiva, mas esta foi aumentada depois de 21 dias. Todos os materiais, menos o IRM, demonstraram não serem solúveis.

Torabinejad et al. ${ }^{16}$ (1995b) avaliaram os efeitos antibacterianos do MTA, amál- 
gama, Super-EBA e óxido de zinco e eugenol. Os materiais frescos, ou após 24 horas de manipulação, foram colocados em contato em placas semeadas com 9 tipos de bactérias facultativas e 7 anaeróbias estritas. Nenhum material foi completamente efetivo contra todas as bactérias, o que demonstra que os materiais não são antimicrobianos.

Continuando a série de estudos, Torabinejad et al. ${ }^{17}$ (1997) verificaram histologicamente a resposta dos tecidos perirradiculares de macacos perante o MTA e amálgama. Doze canais maxilares foram obturados e restaurados. Retalhos foram abertos e os ápices apicectomizados e retropreparados com brocas, sendo metade das cavidades retrobturadas com MTA e amálgama respectivamente. Depois de 5 meses os blocos contendo os ápices foram analisados histologicamente. Cinco das seis regiões do grupo MTA não mostraram nenhuma inflamação e as retrobturações foram cobertas com uma camada de cemento neoformado, enquanto todas do grupo amálgama demonstraram inflamação e nenhuma formação de cemento.

Avaliando histologicamente a reação tecidual da tíbia e mandíbula de porcos perante o MTA, amálgama, IRM e SuperEBA, Torabinejad et al. ${ }^{18}$ (1998) fecham o ciclo inicial de estudos referentes ao uso clínico do MTA. Vinte animais foram anestesiados, tiveram cavidades ósseas preparadas na tíbia e receberam recipientes de teflon contendo os materiais, sendo estes voltados para o osso. Dez dias após, os animais receberam recipientes na mandíbula da mesma maneira descrita. Depois de 80 dias os blocos das regiões foram processados para histologia. Os resultados mostraram que a reação tecidual diante do MTA foi a mais favorável entre todos os materiais, sendo a resposta inflamatória significativamente $(p<0,01)$ menor. Foi observada, também, formação de tecido mineralizado anexo ao MTA.

Revisando a literatura, com foco em fatores que contribuam para o sucesso, a longo prazo, de procedimentos cirúrgicos envolvendo materiais retrobturadores, Johnson $^{19}$ (1999) coloca diversas considerações acerca da seleção desse tipo de material. O autor revisa o uso de amálga- ma, IRM e Super-EBA, resina composta e MTA. Como conclusão, a escolha do material adequado varia em cada caso e cada filosofia de trabalho, ressaltando-se as vantagens e desvantagens de cada material, e que não existe um consenso na literatura para a indicação de um material em especial, devido ao fato de não haver trabalhos em humanos bem controlados e por longos períodos. O MTA é observado como um material novo com grande potencial de se tornar o material de escolha em retrobturações, devido a sua biocompatibilidade, indução de tecidos minerais, microinfiltração e adaptação marginal.

A citotoxicidade do MTA, Super-EBA e amálgama de prata, em células humanas do ligamento periodontal, foi mensurada por Keiser et al. ${ }^{20}$ (2000). Dois grupos, um com os materiais recém-manipulados e outro com os mesmos após 24 horas de manipulação, foram processados para cultura de células. O teste de citotoxicidade se deu por meio de diluições de cultura com células viáveis em contato com os materiais, passível de ser quantificado. O MTA se mostrou significativamente $(p<$ $0,05)$ menos citotóxico no grupo de amostras frescas de baixa concentração e mais citotóxico após 24 horas em alta e baixa concentração. Os autores sustentam o uso de MTA em ambientes periapicais.

Buscando confirmar a biocompatibilidade do MTA em retrobturações in vivo, Economides et al. ${ }^{21}$ (2003) verificaram a resposta perirradicular do MTA e IRM em dentes caninos. Dois cães tiveram 21 dentes tratados endodonticamente e selados. Durante o mesmo ato, os dentes foram ressectados e retrobturados com MTA (n = 14) ou IRM $(\mathrm{n}=8)$. Após 1 -2 semanas ou 3-4 semanas, os blocos de mandíbula foram para histologia e MEV. O MTA se mostrou significativamente mais biocompatível que o IRM, produzindo muito pouca inflamação, formação de osso e formação de tecido mineralizado sobre o material em todos os espécimes no tempo de 3-4 semanas.

Lasers de alta potência na endodontia e cirurgia apical

Stabholz et al. ${ }^{22,23}$ (1992a, 1992b) foram os pioneiros em verificar a ação do
$A \cup N \quad C A$

AUN CE

GAVINI G

CIRURGIA

APICAL:

TÉCNICAS,

TECNOLOGIA E

MATERIAIS

NA BUSCA DO

SUCESSO
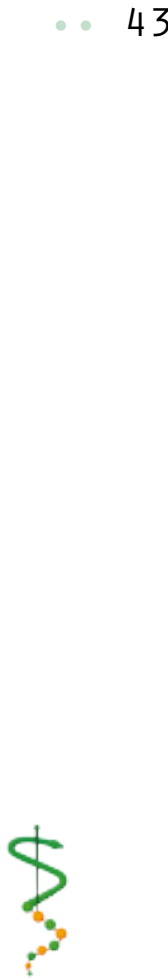

REVISTA DE ODONTOLOGIA DA UNIVERS I DADE Cidade de São PAULO

$2010 ; 22(1): 39-$ 49, JAN-ABR 
AUN CA

AUN CE

GAVINI G

CIRURGIA

APICAL:

TÉCNICAS,

TECNOLOGIA E

MATERIAIS

NA BUSCA DO

SUCESSO

$44 \ldots$

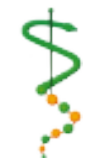

REVISTA DE

ODONTOLOGIA DA

UNIVERSIDADE

CIDADE DE SÃO

PAULO

$2010 ; 22(1): 39-$

49, JAN-ABR laser de Nd:YAG em superfícies ressectadas, retrocavidades e no selamento retrógrado. Sessenta dentes unirradiculares ( $n=10)$ foram divididos aos pares em 3 grupos de acordo com a técnica e retropreparo: pares A e B foram obturados, apicectomizados com brocas em alta rotação e receberam retrocavidades. Nos pares C e $\mathrm{D}$ as raízes foram preparadas como descrito no primeiro par, exceto pela não realização de uma retrocavidade, e nos pares E e $F$ as raízes não foram preparadas, mas foram apicectomizadas e retropreparadas como em A e B. Todas as superfícies apicais e retropreparos foram irradiados com $3 \mathrm{~W}, 20 \mathrm{~Hz}$ e $150 \mathrm{~mJ}$ no primeiro estágio (sem refrigeração) e 1,9 W, $20 \mathrm{~Hz}$ e 95 mJ no segundo (com refrigeração a água). As retrobturações foram realizadas com amálgama. Todas as raízes permaneceram imersas em azul de metileno a 0,5\% por 48 horas e escores de avaliadores atribuídos. A penetração de corante nos grupos irradiados foi significativamente menor $(p$ $<0,05)$ que nos grupos-controle. Alguns espécimes foram observados em MEV, revelando: fusão e derretimento dentinário; formação de "gotas" e globulações dentinárias; uma incompleta e descontínua resolidificação e recristalização dentinária.

Num estudo clássico, Moritz et al. ${ }^{24}$ (1997) verificaram a ação antimicrobiana, a temperatura na superfície radicular e a penetração de corante na dentina radicular irradiada com laser Diodo de alta potência $(810 \mathrm{~nm})$. Na avaliação bactericida, 44 canais foram preparados e esterilizados. Bactérias foram inoculadas intracanal por 48 horas a $37^{\circ} \mathrm{C}$. O laser foi aplicado nos parâmetros de 2, 3 e $4 \mathrm{~W}$ e taxas de pulsos de 0,01 e 0,02. Outras raízes receberam irradiações intracanal, sendo a temperatura da superfície radicular controlada por espectroscópio infravermelho. Canais preparados cuja camada de magma dentinário não havia sido removida foram irradiados com 2, 3 e $4 \mathrm{~W}$ e armazenados em fucsina a $1 \%$ por 1 hora. Cinco dos 44 canais apresentaram novo crescimento bacteriano após 28 dias. A temperatura média da superfície apical permaneceu em $6^{\circ} \mathrm{C}$. A penetração de corante foi muito diminuída nas potências de 2 e $3 \mathrm{~W}$ e nula aos $4 \mathrm{~W}$, comprovando, em MEV, a obliteração e diminuição da permeabilidade dentinária. O laser de Diodo 810nm pode ser diretamente comparado ao laser de Nd:YAG segundo os autores, apresentando propriedades similares.

Liu et al. ${ }^{25}$ (1997) avaliaram o selamento superficial de túbulos dentinários cervicais causado pela irradiação de $\mathrm{Nd}$ :YAG. Blocos de dentina foram irradiados com $30 \mathrm{~mJ}$ e 10 pulsos/seg. Logo após, foram congelados em nitrogênio líquido e cortados transversalmente. Todos os espécimes foram fotografados em MEV e foram observados fusão e obliteração das entradas de túbulos dentinários em todos os espécimes irradiados, sendo $4 \mu \mathrm{m}$ a profundidade média de selamento.

Camargo et al. ${ }^{26}$ (1999) verificaram a permeabilidade de retrobturações após apicectomia. Sessenta e dois dentes foram preparados e divididos em 4 grupos, de acordo com o tipo de apicectomia e tratamento apical: G1, apicectomia com brocas diamantadas em alta rotação e preparo da retrocavidade com brocas em baixa rotação; G2, apicectomia com brocas em alta rotação, preparo da retrocavidade em baixa rotação e irradiação com Nd:YAG ( $1 \mathrm{~W}, 15 \mathrm{~Hz}, 30 \mathrm{seg}$ ) em toda superfície ressectada e retrocavidade; G3, apicectomia com laser Er:YAG (400 m), 6 HZ, sob refrigeração) e preparo da retrocavidade em baixa rotação e G4 da mesma maneira que G3, porém, ao final, era aplicado o laser Nd:YAG da mesma maneira que no G2. Todos os espécimes foram retrobturados com Super-EBA e permaneceram em azul de metileno a 1\% por 12 horas. Ambos os grupos tratados com Nd:YAG apresentaram os menores valores de microinfiltração, sendo o G4 significante ( $p$ $<0,05)$ perante os outros grupos.

Oliveira et al. ${ }^{27}$ (2004) estudaram os efeitos de lasers de alta potência sobre o selamento retrógrado. Três grupos $(n=8)$ de raízes foram divididos de acordo com o método de apicectomia e tratamento da superfície apical com lasers: $\mathrm{Gl}$, apicectomia com Er:YAG $(350 \mathrm{~mJ}, 4 \mathrm{~Hz}, 28,2 \mathrm{~J} /$ $\mathrm{cm} 2)$, tratamento da superfície $(129 \mathrm{~mJ}$, $4 \mathrm{~Hz}, 69,1 \mathrm{~J} / \mathrm{cm} 2)$ e preparo da retrocavidade (350 mJ, $4 \mathrm{~Hz}, 201,5 \mathrm{~J} / \mathrm{cm} 2)$; GII, apicectomia similar ao grupo $\mathrm{I}$, tratamento da superfície e confecção da retrocavida- 
de com Nd:YAG $(100 \mathrm{~mJ}, 15 \mathrm{~Hz}, 1,5 \mathrm{~W})$ e GIII controle. Logo após os espécimes imersos em azul de metileno $0,5 \%$ por 48 horas e observados em MEV. O Gll apresentou estatisticamente a menor penetração de corante. A análise em MEV revelou obliteração de túbulos no Gll e abertura de túbulos no GI.

A capacidade bactericida de lasers de alta potência através da dentina foi avaliada por Schoop et al. ${ }^{28}$ (2004). Discos de dentina foram obtidos, esterilizados e inoculados, em um lado somente, com E. coli e E. faecalis. Os lasers de Nd:YAG, Diodo 810 nm, Er:YAG e Er,Cr:YSGG foram utilizados em duas potências, 1 e 1,5 W e irradiados 5 vezes, no modo contato, no lado não inoculado. Todos os lasers foram capazes de reduzir significativamente a quantidade de bactérias na regulagem de $1,5 \mathrm{~W}$.

Souza et al. ${ }^{29}$ (2006) verificaram que o laser Diodo $810 \mathrm{~nm}$ poderia aumentar o selamento apical em cavidades retrógradas obturadas com MTA. Vinte raízes ( $\mathrm{n}$ = 10) foram obturadas. Os ápices foram cortados e retropreparados com brocas. O G1 foi retrobturado com MTA e o G2 sofreu irradiação (1 W, 20 s) na superfície apical e na retrocavidade antes da retrobturação. Os espécimes foram imersos em corante rodamina B a $1 \%$ por 72 horas. Não houve diferença estatística significante entre os dois grupos ( $p>0,05)$, evidenciando-se que a irradiação com Diodo não proporcionou aumento do selamento retrógrado.

\section{I SCUSSÃO}

A Endodontia está em constante aprimoramento, tanto em suas bases teóricas e filosóficas como em sua técnica operatória. Porém, uma parte dessa problemática ainda permanece sem resolução, principalmente a chamada "infecção refratária", a qual resiste à terapia endodôntica e diminui significativamente o índice de sucesso de retratamentos. Esse tipo de infecção pode ocorrer devido a diversos fatores como: anatomia do sistema de canais, qualidade da obturação, conduta técnica, biosegurança, tempo de contaminação e, primordialmente, pelo biofilme intra e extrarradicular. Para Nair ${ }^{30}$ (2007), o biofilme intrarradicular, permeado no delta e ramificações do terço apical de um tratamento mal conduzido, muitas vezes é o principal fator etiológico microbiano da periodontite apical pós-tratamento.

Os autores ainda demonstram controvérsias quando indicam um retratamento cirúrgico ou não cirúrgico. Allen et al. ${ }^{4}$ (1989), Kvist e Reit ${ }^{6}$ (1999) não encontraram diferença entre o método de retratamento conservador e o radical em seus estudos clínicos in vivo, sendo os índices de sucesso $72,2 \%$ e $60 \%$, respectivamente, para casos tratados não cirurgicamente. Mead et al. ${ }^{7}$ (2005) criticaram metodologias empregadas em diversos estudos que compararam clinicamente as duas técnicas, principalmente quanto ao controle padronizado dos casos, constatando que muito pouco se pode correlacionar na literatura sobre esse assunto. Já von Arx et al. ${ }^{8}$ (2007), em seu estudo clínico com técnicas operatórias mais modernas, como o uso de ultrassom no retropreparo e microscopia ótica, conseguiram bons índices de sucesso $(92,5 \%$ e $83,8 \%$ respectivamente), indicando a técnica cirúrgica como opção para resolução de infecções refratárias.

Dentre os diversos motivos que podem levar um caso diretamente à resolução cirúrgica, temos como principais: a presença de núcleos e pinos extensos; aberrações anatômicas apicais, radiculares e periodontais; perfurações apicais; presença de corpo estranho na região apical; traumas radiculares; persistência de lesões, sinais e sintomas em retratamentos não cirúrgicos bem realizados. Por muitos anos não se soube explicar por que casos bem retratados não cirurgicamente falhavam. Nair ${ }^{30}(2007)$ justifica que por muitos anos as metodologias de pesquisa microbiológica foram inadequadas na busca da verificação de bactérias e microrganismos em biofilmes intra e extrarradiculares. Com o aprimoramento das técnicas de verificação microbiológica, Nair et al. ${ }^{31}$ (1990) descrevem a presença de biofilmes intrarradiculares, e Tronstad et al. ${ }^{32}$ (1987) descreveram a formação de infecções endodônticas extrarradiculares, comprovando a presença de bactérias dentro de granulomas, cistos e superfícies radiculares
$A \cup N \quad C A$

AUN CE

GAVINI G

CIRURGIA

APICAL:

TÉCNICAS,

TECNOLOGIA E MATERIAIS

NA BUSCA DO

SUCESSO
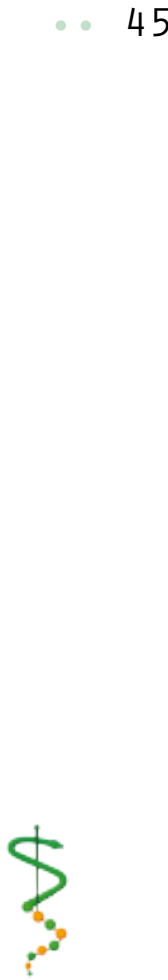

REVISTA DE ODONTOLOGIA DA UN I VERS I DADE Cidade de São PAULO

2010; 22(1): 39 49, JAN-ABR 
$A \cup N \quad C A$

AUN CE

GAVINI G

CIRURGIA

APICAL:

TÉCNICAS,

TECNOLOGIA E

MATERIAIS

NA BUSCA DO

SUCESSO

46

REVISTA DE

ODONTOLOGIA DA

UNIVERSIDADE

CIDADE DE SÃO

PAULO

$2010 ; 22(1): 39-$

49, JAN-ABR apicais. Hoje é consenso entre os pesquisadores a presença de biofilme e espécies específicas de microorganismos nos casos de infecções refratárias. Por esses motivos, se torna necessário o contínuo estudo da técnica de cirurgia apical, na busca de melhores índices de sucesso.

O manejo do ápice durante a cirurgia endodôntica ainda está em constante aperfeiçoamento. A ressecção apical, confecção da retrocavidade, tratamento da superfície ressectada e retrobturação são passos cirúrgicos primordiais. Gutmann e Pitt Ford ${ }^{5}$ (1993) ressaltam diversos fatores essenciais para o adequado manejo das cirurgias apicais, sendo a apicectomia e retrobturação os principais. O estudo realizado por Gilheany et al. ${ }^{33}$ (1994) justifica o corte do ápice perpendicular ao longo eixo da raiz, pois esta proposta diminui significativamente a microinfiltração da retrobturação, gerando menor comunicação entre o sistema endodôntico e os tecidos circundantes. Testori et al. ${ }^{10}$ (1999), demonstraram um aumento significante no sucesso da cirurgia apical quando do uso de pontas ultrassônicas no retropreparo. É importante notar que diversos detaIhes operatórios como tipo de broca, velocidade do motor (alta ou baixa potência), potência ultrassônica, tipo de ponta ultrasônica, ângulo de corte, profundidade da retrocavidade e tempo de uso do ultrasom, entre outros, são fatores relevantes. Todos podem influenciar diretamente na microinfiltração retrógrada devido a formação de cracks, abertura ou exposição de túbulos dentinários na superfície apical ressectada, espessura dentinária das paredes da retrocavidade e regularidade do preparo e da superfície apical ressectada (Tobón-Arroyave et al. ${ }^{11}$ 2007).

A retrobturação requer atenção especial do endodontista, não somente pela sua dificuldade técnica, mas devido à escolha do material a ser empregado, podendo este influenciar drasticamente no prognóstico cirúrgico. Não somente o material em si, mas conjuntamente com sua adaptação, quando inserido na retrocavidade e nível de selamento alcançado neste sítio após sua presa.

Como revisado, o MTA possui como pontos favoráveis: ótima biocompatibili- dade, capacidade de presa na umidade, selamento superior na presença de umidade ou sangue, boa adaptação marginal, radiopacidade, não corrosivo, não reabsorvível, antifúngico e indutor de neoformação tecidual periodontal (Economides et al. ${ }^{21}, 2003$; Keiser et al. ${ }^{20}, 2000$; Johnson $^{19}$, 1999; Torabinejad et al. ${ }^{12}$, 1993; Torabinejad et al. ${ }^{18,13,17,14}, 1994,1995 \mathrm{c}$, 1997, 1998). Como pontos desfavoráveis, o MTA apresenta: difícil manipulação e manejo, não possui capacidade antibacteriana expressiva e oferece pouca resistência a forças de compressão (Torabinejad et al. ${ }^{15,16}$ 1995a, 1995b). Torabinejad e sua equipe (Torabinejad et al. ${ }^{12}, 1993$; To-

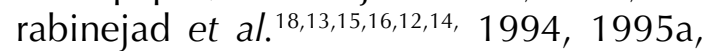
1995b, 1995c, 1997, 1998) praticamente asseguraram o uso responsável e embasado do MTA como material retrobturador de escolha.

Um "boom" nas tecnologias ópticas e fotônicas industriais, aliado aos novos conceitos e teorias da Medicina sobre a interação luz/tecido, trouxeram, nas décadas de 80 e 90, possibilidades de aplicação de diversos tipos de lasers em tecidos bucais e dentais. Os lasers de alta potência, ou "cirúrgicos", têm a capacidade de emitir grande quantidade de energia em pequenos focos e/ou pulsos, o que lhes confere a capacidade de corte, abertura ou selamento/derretimento de tecidos duros (Camargo et al. ${ }^{26}, 1999$; Liu et al. ${ }^{25}, 1997$; Moritz et al. ${ }^{24}, 1997$; Oliveira et al. ${ }^{27}, 2004$; Stabholz et al. ${ }^{22,}{ }^{23}$ 1992a, 1992b), além do desejado poder antimicrobiano (Moritz et al. ${ }^{34}$ 2000; Schoop et al. $\left.{ }^{28}, 2004\right)$. Inicialmente os lasers de alta potência $\mathrm{CO}^{2}, \mathrm{Nd}: Y A G$ e Er:YAG viraram foco das atenções na Endodontia e Periodontia. Com o tempo, novos lasers como o Diodo $810 \mathrm{~nm}$ e, mais recentemente, o érbio cromo (Er,Cr:YSGG), também entraram para lista dos mais estudados.

A partir dos primeiros relatos sobre o efeito de fusão e ressolidificação de tecido dentinário, após irradiação com os lasers Nd:YAG e Diodo, observado em MEV por Stabholz et al. ${ }^{22,23}$ (1992a, 1992b) e Moritz et al. ${ }^{24}$ (1997) respectivamente, surgiu a proposta de se conseguir a diminuição da permeabilidade dentinária na superfície apical ressectada, inclusive nas paredes 
da retrocavidade. Essa alteração na morfologia e ultraestrutura dentinária, principalmente pelo brusco e poderoso aumento de temperatura no foco do raio laser, poderia otimizar o selamento e adaptação marginal dos materiais retrobturadores, e melhorar o prognóstico das cirurgias apicais. Mas poucos estudos procuraram verificar os efeitos dessas interações na microinfiltração retrógrada de maneira padronizada e sistemática (Camargo et al. ${ }^{26}, 1999$; Oliveira et al. ${ }^{27}, 2004$; Souza et al. ${ }^{29}, 2006$; Stabholz et al. $\left.{ }^{22}, 1992 a\right) . ~ E m$ todos esses estudos, a microinfiltração de corante foi o único método utilizado para avaliar a microinfiltração de diversos tipos e materiais retrobturadores. Nenhum estudo até os dias atuais verificou, in vivo ou clinicamente em humanos, se este efeito pode realmente melhorar o índice de sucesso de cirurgias apicais. Outra grande problemática dos estudos com lasers é a falta de protocolos ou padronizações nos parâmetros de irradiação dos diferentes lasers.

Esta revisão não teve como objetivo exaurir a literatura acerca da cirurgia apical, mas selecionar alguns dos principais tópicos e discuti-los. Cada um dos temas abordados mereceria uma específica revisão, mais profunda e detalhada, porém, consideramos mais proveitosa a ideia de aproximar tópicos inter-relacionados e interdependentes como os apresentados. A constante pesquisa literária é de fundamental importância quando se procura o aperfeiçoamento, norteando e delimitando as bases teóricas que vão reger as técnicas empregadas nas mais diversas especialidades. Assim, esperam-se novas revisões de literatura que possam promover conhecimento e desenvolvimento para a ciência moderna.

\section{REFERÊNCIAS}

1. Aun CE, Silva LX. Observação in vitro da infiltração marginal de obturações retrógradas em dentes apicectomizados com e sem aplicação de laser CO2. Rev Odontol UNICID. 1995 jul-dez;7(2):73-81.

2. Aun CA, Aun CE, Poloniato M. Avaliação da microinfiltração do MTA e Super-EBA com e sem a aplicação de laser CO2 e análise complementar em MEV. Rev Odontol UNICID. 2004 set-dez;16(3):241-6.

3. Aun CA, Gavini G, Aun CE. Influência dos lasers Nd:YAG e diodo na microinfiltração retrógrada do MTA in vitro. Braz Oral Res. 2004; 18 Supp: 209.

4. Allen RK, Newton CW, Brown CE Jr. A statistical analysis of surgical and nonsurgical endodontic retreatment cases. J Endod. 1989 Jun;15(6):261-6.

5. Gutmann JL, Pitt Ford TR. Management of the resected root end: a clinical review. Int Endod J. 1993 Sep; 26(5): 273-83.

6. Kvist T, Reit C. Results of endodontic retreatment: a randomized clinical study comparing surgical and nonsurgical procedures. J Endod. 1999 Dec; 25 (12): 814-7.

7. Mead C, Javidan-Nejad S, Mego ME, Nash B, Torabinejad M. Levels of evidence for the outcome of endodontic surgery. J Endod. 2005 Jan; 31(1): 19-24.

8. von Arx T, Jensen SS, Hänni S. Clinical and radiographic assessment of various predictors for healing outcome 1 year after periapical surgery. J Endod. 2007 Feb; 33(2): 123-8.

AUN CA

AUN CE

GAVINI G

CIRURGIA

APICAL:

TÉCNICAS,

teCNOLOGIA E

MATERIAIS

NA BUSCA DO

SUCESSO

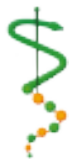




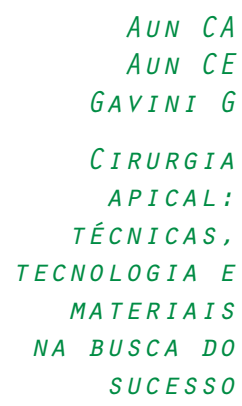

48

9. Morgan LA, Marshall JG. The topography of root ends resected with fissure burs and refined with two types of finishing burs. Oral Surg Oral Med Oral Pathol Oral Radiol Endod. 1998 May; 85(5): 585-91.

10. Testori T, Capelli M, Milani S, Weinstein RL. Success and failure in periradicular surgery: a longitudinal retrospective analysis. Oral Surg Oral Med Oral Pathol Oral Radiol Endod. 1999 Apr; 87(4): 493-8.

11. Tobón-Arroyave SI, Restrepo-Pérez MM, Arismendi-Echavarría JA, Velásquez-Restrepo Z, Marín-Botero ML, García-Dorado EC. Ex vivo microscopic assessment of factors affecting the quality of apical seal created by root-end fillings. Int Endod J. 2007 Aug; 40(8): 590-602.

12. Torabinejad M, Watson TF, Pitt Ford TR. Sealing ability of a mineral trioxide aggregate when used as a root end filling material. J Endod. 1993 Dec; 19(12): 591-5.

13. Torabinejad M, Higa RK, McKendry DJ, Pitt Ford TR. Dye leakage of four root end filling materials: effects of blood contamination. J Endod. 1994 Apr; 20(4): 159-63.

14. Torabinejad M, Smith PW, Kettering JD, Pitt Ford TR. Comparative investigation of marginal adaptation of mineral trioxide aggregate and other commonly used rootend filling materials. J Endod. 1995c Jun; 21(6): 295-9.

15. Torabinejad M, Hong CU, McDonald F, Pitt Ford TR. Physical and chemical properties of a new root-end filling material. J Endod. 1995a Jul; 21(7): 349-53.

16. Torabinejad M, Hong CU, Pitt Ford TR, Kettering JD. Antibacterial effects of some root end filling materials. J Endod. 1995b Aug; 21(8): 403-6.

17. Torabinejad M, Pitt Ford TR, McKendry DJ, Abedi HR, Miller DA, Kariyawasam SP. Histologic assessment of mineral trioxide aggregate as a root-end filling in monkeys. J Endod. 1997 May; 23(4): 225-8.

18. Torabinejad M, Ford TR, Abedi HR, Kariyawasam SP, Tang HM. Tissue reaction to implanted root-end filling materials in the tibia and mandible of guinea pigs. J Endod. 1998; 24(7): 468-71.

19. Johnson BR. Considerations in the selection of a root-end filling material. Oral Surg Oral Med Oral Pathol Oral Radiol Endod. 1999 Apr; 87(4): 398-404.

20. Keiser K, Johnson CC, Tipton DA. Cytotoxicity of mineral trioxide aggregate using human periodontal ligament fibroblasts. J Endod. 2000 May; 26 (5): 288-91.

21. Economides N, Pantelidou O, Kokkas A, Tziafas D. Short-term periradicular tissue response to mineral trioxide aggregate (MTA) as root-end filling material. Int Endod J. 2003;36(1):44-8.

22. Stabholz A, Khayat A, Weeks DA, Neev J, Torabinejad M. Scanning electron microscopic study of the apical dentine surfaces lased with ND:YAG laser following apicectomy and retrofill. Int Endod J. 1992a Nov; 25(6): 288-91.

23. Stabholz A, Khayat A, Ravanshad SH, McCarthy DW, Neev J, Torabinejad M. Effects of Nd:YAG Laser on Apical Seal of Teeth after Apicoectomy and Retrofill. J Endod. 1992b Aug; 18(8): 371-5.

24. Moritz A, Gutknecht N, Goharkhay K, Schoop U, Wernisch J, Sperr W. In vitro irradiation of infected root canals with a diode laser: results of microbiologic, infrared spectrometric, and stain penetration examinations. Quintessence Int. 1997 Mar; 28(3): 205-9.

ODONTOLOGIA DA

UNIVERS I DADE

CIDADE DE SÃO

PAULO

$2010 ; 22(1): 39-$

49, JAN-ABR

25. Liu HC, Lin CP, Lan WH. Sealing depth of Nd:YAG laser on human dentinal tubules. J Endod. 1997 Nov; 23(11): 691-3. 
26. Camargo SCC, Gavini G, Eduardo CdP, Aun CE, Ribeiro LWN, Coil JM. Association of Er:YAG and Nd:YAG irradiation for apicoectomy and retrofilling cavity preparation compared to conventional technique: a permeability study. In: Conference on Lasers in Dentistry 1999, San José. Society of Proto-Optical Instrumental Enginners, 1999, v.3593. p.2-5.

27. Oliveira RG, Gouw-Soares S, Baldochi SL, Eduardo CP. Scanning electron microscopy (SEM) and optical microscopy: effects of Er:YAG and $\mathrm{Nd}$ :YAG lasers on apical seals after apicoectomy and retrofill. Photomed Laser Surg. 2004 Dec; 22(6): 533-6.

28. Schoop U, Kluger W, Moritz A, Nedjelik N, Georgopoulos A, Sperr W. Bactericidal effect of different laser systems in the deep layers of dentin. Lasers Surg Med. 2004; 35(2): 111-6.

29. Souza EB, de Amorim CV, Lage-Marques JL. Effect of diode laser irradiation on the apical sealing of MTA retrofillings. Braz Oral Res. 2006 Jul-Sep; 20(3): 231-4.

30. Nair PNR. Falhas endodônticas: a patologia da periodontite apical pós-tratamento. In: Cohen S, Hargreaves KM. Caminhos da polpa. $9^{a}$ ed. Rio de Janeiro: Elsevier; 2007. p. 918-943.

31. Nair PN, Sjögren U, Krey G, Kahnberg KE, Sundqvist G. Intraradicular bacteria and fungi in root-filled, asymptomatic human teeth with therapy-resistant periapical lesions: a long-term light and electron microscopic follow-up study. J Endod. 1990 Dec; 16(12): 580-8.

32. Tronstad L, Barnett F, Riso K, Slots J. Extraradicular endodontic infections. Endod Dent Traumatol. 1987 Apr; 3(2): 86-90.

33. Gilheany PA, Figdor D, Tyas MJ. Apical dentin permeability and microleakage associated with root end resection and retrograde filling. J Endod. 1994 jan;20 (1) :22-6.

34. Moritz A, Jakolitsch S, Goharkhay K, Schoop U, Kluger W, Mallinger R, et al. Morphologic changes correlating to different sensitivities of escherichia coli and enterococcus faecalis to Nd:YAG laser irradiation through dentin. lasers Surg Med. 2000; 26(3): 250-61.

Recebido em: 28/01/2008

Aceito em: 01/10/2009 